\title{
Ensino Não Presencial e Limitações Digitais: Análise de Indicadores da Produção Científica entre 2004 e 2021
}

\section{E-Learning and Digital Limitations: Analysis of Scientific Production Indicators Between 2004 and 2021}

\section{Resumo}

Errol Fernando Zepka Pereira Junior $^{1 *}$

Tanise Paula Novello ${ }^{2}$

Rafael Camargo Ferraz ${ }^{3}$

Pedro Antônio De Melo ${ }^{1}$

Livia Castro D'Avila ${ }^{4}$

1 Universidade Federal de Santa

Catarina - UFSC - R. eng. Agronômico

Andrei Cristian Ferreira, s/n - Trindade,

Florianópolis - SC - Brasil.

*zepkaef@gmail.com

${ }^{2}$ Universidade Federal de Pelotas

UFPel - R. Gomes Carneiro, 01 - Balsa,

Pelotas - RS - Brasil.

3 Universidade Federal do Pampa

Unipampa - Av. Maria Anunciação

Gomes Godoy, 1650 - Bagé

RS - Brasil.

${ }^{4}$ Universidade Federal do Rio Grande -

FURG. Av. Itália, s/n - km 8 - Carreiros,

Rio Grande - RS - Brasil.
Em decorrência da pandemia da Covid-19, emergiu a necessidade de outras formas de viver decorrentes do isolamento social. Os processos de ensinar e-learning (não presencial) apoiados pelas tecnologias digitais se tornou uma alternativa. O presente artigo tem como objetivo analisar os indicadores da produção científica mundial acerca das limitações digitais no ensino e-learning. Nesse sentido, foi realizada uma busca de produções científicas no período de 2004 a 2021 que versam sobre a temática da limitação digital. A partir do refinamento da busca, definiram-se 375 trabalhos que serão discutidos neste artigo. A partir da análise, apresentam-se os indicadores desta produção, com destaque para Taiwan, e uma conversa teórica acerca dos tipos de educação não presencial, trabalhados como educação a distância; A educação presencial apoiada pelas TIC; A educação presencial com 20\% de sua operacionalização a distância; Educação emergencial remota (Covid-19).

Palavras-chave: ensino não presencial. Limitação digital. Produção científica. Bibliometria.

\section{(c) (i)}

Recebido 28/05/2021

Aceito 28/09/2021

Publicado 05/10/2021

\section{COMO CITAR ESTE ARTIGO}

ABNT: PEREIRA JUNIOR, E. F. Z. et al. Ensino Não Presencial e Limitações Digitais: Análise de Indicadores da Produção Científica entre 2004 e 2021. EaD em Foco, v. 11, n. 2, e1503, 2021. https://doi.org/10.18264/eadf.v11i2.1503 


\title{
E-Learning and Digital Limitations: Analysis of Scientific Production Indicators Between 2004 and 2021
}

\begin{abstract}
Due to the Covid-19 pandemic, there was a need for other ways of living due to social isolation. The processes of teaching e-learning (not in person) supported by digital technologies has become an alternative. This article aims to analyze the indicators of global scientific production about digital limitations in e-learning teaching. In this sense, a search for scientific productions was carried out in the period from 2004 to 2021 that deal with the theme of digital limitation. From the refinement of the search, 375 works were defined that will be discussed in this article. From the analysis, the indicators of this production are presented, with emphasis on Taiwan, and a theoretical conversation about the types of non-face-to-face education, worked as: Distance education; Faceto-face education supported by ICT; Face-to-face education with 20\% of its operationalization at distance; and remote emergency education (Covid-19).
\end{abstract}

Keywords: Non-classroom teaching. Digital limitation. Scientific production. Bibliometrics.

\section{Introdução}

Em 2020, o mundo foi surpreendido pelo surto do vírus SARS-COV-2, agente etiológico causador da doença do Covid-19, que se alastrou rapidamente por todos os lugares, causando uma pandemia ainda em curso e colocando os países em emergência, alerta e isolamento social, uma vez que o vírus se reproduz mais facilmente em aglomerações (SPINELLI; PeLLINO, 2020). Tendo em vista o perigo de contágio que existe nas aglomerações regulares dos ambientes educacionais, foram necessários, por parte dos governos, decretos que fechassem o funcionamento presencial das salas de aula em todas as esferas educacionais, afetando assim 1,7 bilhão de estudantes de diferentes classes sociais e faixas etárias por todo o mundo (SENHORAS, 2020).

Todavia, Bezerra (2020) aponta que os cursos de graduação e pós-graduação estão buscando usar metodologias remotas para a continuidade dos períodos letivos atuais. Essas metodologias buscam proporcionar ao usuário a sensação de imersão que é estar na sala de aula através da navegação e interação no Ambiente Virtual de Aprendizagem (AVA), ao mesmo tempo em que busca respeitar os princípios educacionais e as abordagens pedagógicas dos docentes, a fim de não ser intransigente em apenas transpor o que acontecia antes, na educação presencial, para apenas um novo modelo denominado e-learning. Esse modelo tem seu termo do inglês "eletronic learning", ou seja, na sua tradução "aprendizado eletrônico", tal modelo teve sua ampliação devido à expansão das tecnologias digitais, especialmente pela aquisição dos dispositivos móveis (smartphone, tablet, notebook) e da própria internet, que possibilita a troca imediata de informações e o acesso e compartilhamento de materiais.

Diversos aspectos podem interferir neste momento, gerando dificuldades aos professores, tais como: problemas de acesso, estrutura tecnológica necessária (computador, internet de qualidade, webcam), questões cognitivo-informacionais em não saber usar as Tecnologias da Informação e Comunicação (TIC) ou mesmo situações comportamentais em resistências a não quererem aderir aos novos modelos educacionais (NOVELLO et al, 2020). 
Apesar do novo incentivador ao interesse em pesquisas que versem sobre limitações digitais em educação a distância, não foram localizados no portal de Periódicos da CAPES artigos nacionais ou internacionais publicados sobre bibliometria e/ou análise bibliométrica e/ou revisão sistemática de literatura sobre o assunto, oportunizando um caráter de originalidade para o presente estudo, que tem por objetivo analisar os indicadores da produção cientifica mundial acerca das limitações digitais em educação a distância. Este se desdobra especificamente na realização das buscas e análise bibliométrica, as articulações entre as limitações digitais e as formas de ensino não presencial, finalizando com a proposição de novos estudos para a temática.

\section{Limitações Digitais em Tempos de Covid-19}

Motivados pela pandemia do Covid-19, as instituições de ensino superior (IES) precisaram tomar decisões sobre um plano para a continuidade de suas atividades em formato não presencial. Arruda (2020) explica que há uma confusão nas denominações do modelo, chamados por alguns como educação on-line, educação a distância e mesmo educação remota. Para o autor, apesar de serem colocados como sinônimos, os termos implicam coisas diferentes. enquanto a educação a distância pressupõe o formato como um meio em si mesmo, a educação remota vem a ser uma resposta rápida e elaborada emergencialmente para o período pandêmico.

A educação remota emergencial aparece como uma mudança temporária da entrega dos conteúdos curriculares antes presenciais para um formato alternativo em resposta a uma crise. Esse novo formato faz uma combinação entre práticas dos modelos presenciais e EaD, e objetivam manter-se assim pelo tempo que a crise sanitária do Covid-19 durar (HODGeS et al., 2020). A educação remota pode ser apresentada como semelhante à educação presencial, com práticas como a transmissão das aulas no mesmo período em que aconteceriam as aulas presenciais. Essa transmissão permite, de certa forma, a interação docente-discente e discente-discente, mas a interação pode ser inibida, em especial aos alunos mais tímidos, quando a exposição se torna mais ampla e as aulas passam a ser gravadas e disponibilizadas em ambientes virtuais. Ademais, nessa semelhança ao modelo presencial, a educação remota avança em alguns pressupostos do e-learning ao implementar ferramentas assíncronas de comunicação, como fóruns de discussão.

Nesse sentido, Rocha (2020) escreve que, estando os professores estruturados pelas tecnologias digitais, faz-se necessária uma reelaboração de suas formas de se relacionar com o tempo e o espaço, antes de forma presencial, e agora criando novas maneiras de socialização em rede. A educação remota (chamada pela autora de educação on-line) tem o potencial de contribuir para transformar o modo massivo do ensino remoto, promovendo maior e mais abrangente interação entre docentes e discentes. Todavia, para isso, é necessário que se discutam as diferenças conceituais sobre ensino remoto, educação a distância, educação remota e ensino híbrido para compreender as concepções de planejamento: estas serão vistas neste texto como uma discussão dos resultados, na Seção 5 . Além disso, é preciso demonstrar o potencial dos ambientes virtuais de aprendizagem para estimular que docentes usem as interfaces de atividades promovendo mais autonomia na construção do trabalho formativo.

Importante destacar que esse ambiente de interações sociais acontecendo de forma remota, apoiadas pelas tecnologias, pode gerar diversos problemas a serem pensados, por causa das mais diversas limitações digitais que podem aparecer nos usuários dessas redes. As teorias de limitação digital iniciaram em 1986 com os estudos de Barras e seguida de estudiosos como Van Dijk e Hacker (2003), Klecun (2008), Bellini et al. (2010) que ampliaram o conceito de limitação digital. O resumo histórico destes avanços teóricos é apresentado no Quadro 1, baseado no trabalho de Pereira Junior et al. (2019), em que aparecem de forma resumidas as teorias e seus desdobramentos. 
Quadro 1: Limitações digitais - um aporte teórico

\begin{tabular}{|c|c|}
\hline Estudos & Limitações digitais na visão dos autores \\
\hline BARRAS (1986) & $\begin{array}{l}\text { (i) oportunidade: a adequação das atividades realizadas no setor de usuários para } \\
\text { aplicações da nova tecnologia. Isso, obviamente, afeta a taxa na qual a tecnologia é } \\
\text { inicialmente adotada internamente e na indústria; } \\
\text { (ii) usabilidade: da tecnologia que, nos últimos anos, tornou-se uma restrição muito } \\
\text { mais crítica sobre a taxa de inovação no uso de computadores do que o desempe- } \\
\text { nho técnico do hardware. Aqui, a utilidade abrange a disponibilidade e a qualidade } \\
\text { do software, o que proporciona a compatibilidade direta das aplicações do setor } \\
\text { de serviços da tecnologia e a "facilidade de uso" dos procedimentos operacionais } \\
\text { básicos do sistema; } \\
\text { (iii) adaptabilidade: das organizações que instalam o equipamento. Inclui-se, nesse } \\
\text { fator, a resistência da força de trabalho ou gerencial à introdução de novas tecno- } \\
\text { logias, até que ponto os procedimentos de trabalho podem ser ajustados e a taxa } \\
\text { na qual a força de trabalho ser treinada nas habilidades necessárias para usar a } \\
\text { tecnologia. }\end{array}$ \\
\hline $\begin{array}{l}\text { VAN DIJK; } \\
\text { HACKER } \\
(2003)\end{array}$ & $\begin{array}{l}\text { (i) a pessoa não possuir experiência digital, o que é um fato causado pela falta de } \\
\text { interesse do usuário, por medo de computadores ou até mesmo por não se sentir } \\
\text { atraída pela tecnologia, denominado de acesso psicológico; } \\
\text { (ii) a pessoa não ser proprietária de um computador ou não estar conectada - aces- } \\
\text { so material; } \\
\text { (iii) a pessoa não possuir habilidades digitais, o que seria causado por não apresen- } \\
\text { tar um histórico de uso amigável e suficiente da tecnologia, ou pelo fato de ter uma } \\
\text { educação inadequada, além de faltar apoio social - acesso de habilidades; } \\
\text { (iv) a pessoa não ter oportunidades significativas de uso da tecnologia - acesso de } \\
\text { uso. }\end{array}$ \\
\hline $\begin{array}{l}\text { KLECUN } \\
(2008)\end{array}$ & $\begin{array}{l}\text { (i) disparidades no que se refere ao uso de tecnologia da informação e comunicação, } \\
\text { nas quais as limitações de TIC não podem ser evitadas, assemelhando-se a limita- } \\
\text { ções de acesso a serviços de saúde, oportunidades de emprego etc.; } \\
\text { (ii) disparidades entre e dentro de países, nas quais os países desenvolvidos apre- } \\
\text { sentam acesso e utilização de TIC de forma mais avançada do que em países em } \\
\text { desenvolvimento; } \\
\text { (iii) disparidades políticas e sociais, nas quais os problemas avançam de problemas } \\
\text { tecnológicos e de desenvolvimento para aspectos políticos e sociais; } \\
\text { (iv) disparidades que rejeitam a ideia de limitação digital como questão política ou } \\
\text { de desenvolvimento, caso esses dois aspectos fossem considerados, desviariam a } \\
\text { atenção de outros domínios relevantes, como a saúde pública e o meio ambiente. }\end{array}$ \\
\hline $\begin{array}{l}\text { BELLINI et al. } \\
(2010)\end{array}$ & $\begin{array}{l}\text { (i) limitações de acesso: referem-se às dificuldades sociais e materiais do indivíduo } \\
\text { em usar a TIC; } \\
\text { (ii) cognitivo-informacional: refere-se às deficiências do indivíduo em relação às habi- } \\
\text { lidades digitais necessárias para utilizar de forma efetiva a TIC; } \\
\text { (iii) limitação comportamental: refere-se à dificuldade do indivíduo em aplicar as } \\
\text { suas habilidades digitais, ainda que as possua em nível elevado. }\end{array}$ \\
\hline
\end{tabular}

Fonte: Adaptado de Pereira Junior et al. (2019).

Ainda que a lente teórica de Bellini et al. (2010) tenha sido inicialmente articulada voltada a estudos em organizações empresarias, como as indústrias, não invalidou que novas pesquisas fossem feitas ajustando seus princípios teóricos para ambientes educacionais e também a prática docente, como mostram as pesquisas de Pereira Junior et al. (2019), Novello et al. (2021) e Pereira Junior e Novello (2021).

Em Pereira Junior et al. (2019), os autores analisaram as limitações digitais dos usuários na utilização de uma ferramenta de apoio ao planejamento estratégico de uma Secretaria de Educação a Distância de uma universidade federal brasileira, com o objetivo de compreender quais limitações podem ser destacadas como os principais impeditivos ao uso efetivo da tecnologia. As conclusões da pesquisa conduzem a um entendimento de que ainda que uma ferramenta digital possa ser utilizada para diversas atividades, esse sistema pode não ser utilizado em sua total potencialidade, gerando inclusive questões como o esquecimento na inserção de informações no sistema. A pesquisa ainda mostra que os usuários não perce- 
beram se o sistema em si facilita ou atrapalha suas atividades de planejamento, e uma vez que o sistema não esteja internalizado na organização, as pessoas buscarão informações de maneira informal e, assim, considerarão que o não-uso da ferramenta pode não impactar tanto no processo de trabalho, ou seja, na efetividade digital dos participantes do sistema de planejamento.

Aproximando a lente de Bellini et al. (2010), especificamente tem-se a pesquisa de Novello et al. (2021), onde foram analisadas as práticas educativas emergentes nas novas formas de trabalho dos professores e suas limitações digitais durante o trabalho remoto na pandemia do Covid-19. A pesquisa de apresentação do discurso do sujeito coletivo: "Potencialidades e desafios do trabalho remoto", que discutindo as forma de limitações de acesso apontadas pelos professores, estão alinhadas à ausência de artefatos apropriados e/ou dificuldades em configurá-los; além disso, questões ergométricas, como mobiliário e ambiente apropriado também foram apontados. Os autores também arrazoam sobre o impacto do trabalho remoto na rotina e experiências da família e os desafios em alinhar as demandas de trabalho. A conclusão do estudo indica que as limitações apontadas, em sua maioria, não estão vinculadas aos professores, mas sim à falta de outros agentes educacionais como infraestrutura adequada e estabelecimento de espaços apropriados para o diálogo e o desenvolvimento das atividades laborais.

Como apresentado, a pesquisa de Novello et al. (2021) analisa limitações de acesso, que seria apenas um dos eixos do modelo de Bellini et al. (2010) com professores dialogando estas com sua prática docente no período do trabalho remoto da pandemia do Covid-19. Nessa mesma direção, o trabalho de Pereira Junior e Novello (2021), utilizando-se de todo o modelo teórico de Bellini et al. (2010), analisam as três dimensões da limitação digital: a limitação de acesso; a limitação cognitiva- informacional e a limitação comportamental, prescrutando os novos desenhos do processo de trabalho docente para o formato remoto através da intensificação na utilização das tecnologias da informação e comunicação. A seguir, na Figura 1, apresentam-se de forma sintética os achados dessa pesquisa.

Figura 1: Limitações digitais dos professores nos ambientes virtuais de aprendizagem em época de pandemia.

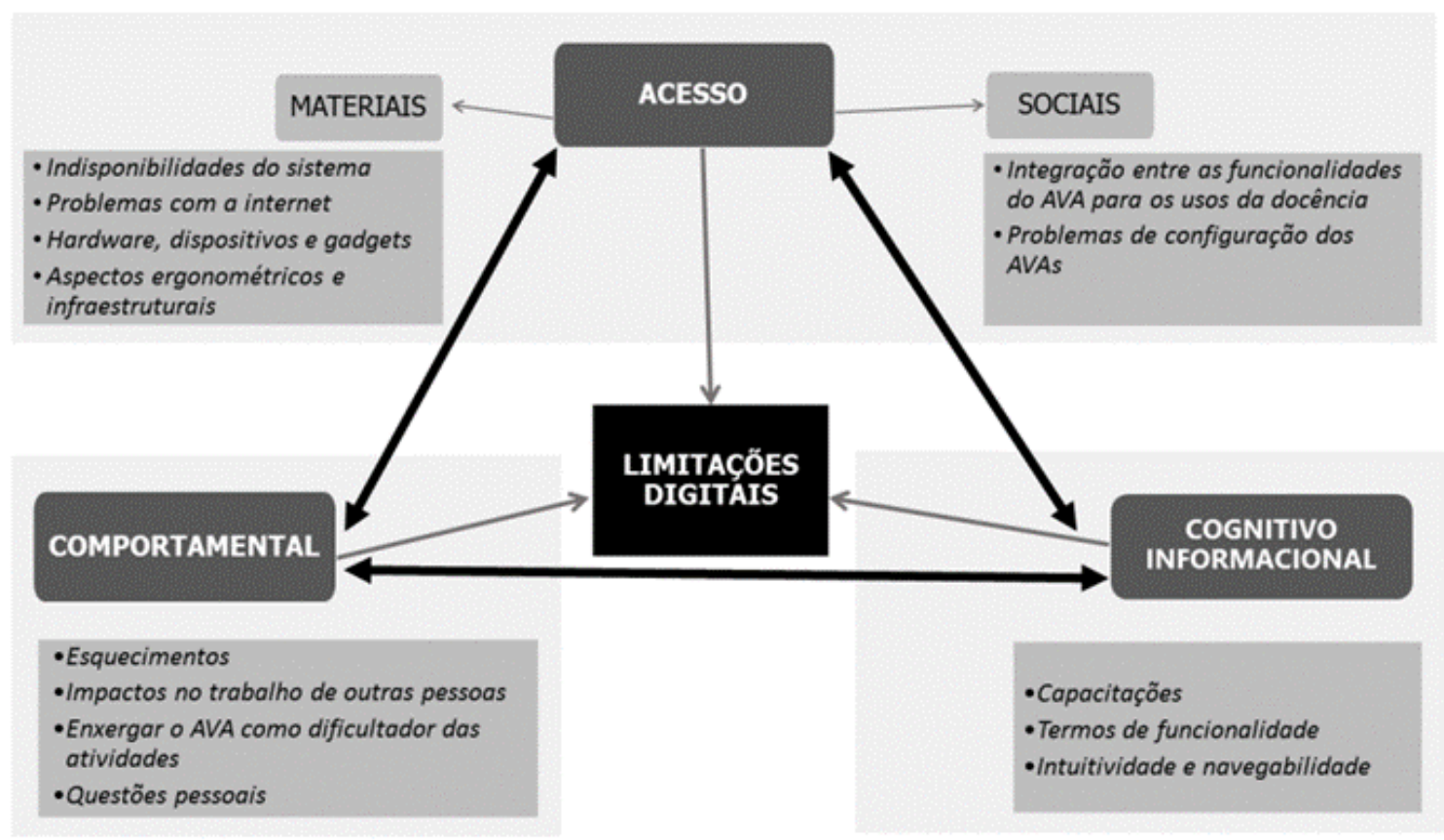

Fonte: Pereira Junior e Novello (2021).

Os autores identificaram noventa limitações digitais, que foram organizadas conforme as três dimensões da limitação digital supracitadas. 
Em limitações de acesso, elencadas em duas subcategorias, aparecem integração entre as funcionalidades do AVA para os usos da docência e problemas de configuração do AVA. Já em limitações materiais, elencadas em quatro subcategorias, a saber: indisponibilidades do sistema; problemas com a internet; hardware, dispositivos e aspectos ergonométricos e infraestruturais. Na sequência, em limitações cognitivo-informacionais, apresentam-se questões acerca das capacitações para utilização dos AVAs; termos e funcionalidades dos sistemas e de praticidade, intuitividade e navegabilidade destes. Por fim, as limitações comportamentais, desdobradas em quatro agrupamentos de limitações, apresentam-se como esquecimentos; impactos no trabalho de outras pessoas; enxergar o AVA como dificultador das atividades e questões pessoais.

\section{Método da Pesquisa}

Esta pesquisa pode ser descrita como exploratória e bibliográfica, pois, através da bibliometria, pode-se mostrar o estado da arte sobre as limitações digitais da educação a distância em estudos presentes na literatura mundial.

Quanto ao propósito, a pesquisa está classificada como pesquisa-diagnóstico, que, para Roesch (2015), tem por propósito levantar e definir problemas e explorar determinado ambiente. A respeito do caráter do estudo, este se enquadra como uma pesquisa exploratória, cujo objetivo principal é realizar uma busca sobre uma determinada situação ou problema para que se possa dar maior compreensão a ele (Malhotra, 2012). Quanto à abordagem, esta pode ser classificada como quantitativa. Richardson (2009) explica que a pesquisa quantitativa pode ser caracterizada através de quantificações, tanto nas modalidades de coleta das informações quanto no tratamento delas por meio das técnicas estatísticas.

A pesquisa utilizou a técnica de coleta dos dados bibliográfica, que, segundo Gil (2018), caracteriza-se com base em materiais já publicados, tais como livros, revistas, jornais, teses, dissertações e anais de eventos científicos. Neste trabalho, os materiais coletados foram os trabalhos científicos publicados em periódicos internacionais sobre consumo sustentável e inovação, nas bases de dados Scopus e Web of Science. Justifica-se a escolha por essas bases a partir do argumento de Souza e Ribeiro (2009), em que os autores apontam que estas bases contemplam um número relevante de periódicos e englobam um número significativo de pesquisas, tendo em seu catálogo diversos dos artigos mais citados no mundo inteiro.

Com relação à técnica de análise de dados bibliométrica, Araújo e Alvarenga (2011) explicam que a pesquisa bibliométrica, através dos processos de levantamentos de dados, tratamento destes e posterior apresentação destes dados, ajuda os pesquisadores a entenderem o processo evolutivo da produção em algum campo de estudos científico de uma determinada área científica.

Para chegar-se a esse resultado, utilizou-se o método baseado no trabalho de Tello-Gamarra et al. (2018), neste os autores buscam (i) identificar a evolução dessas publicações dentro do período estabelecido; (ii) a quantidade de publicações de cada país; (iii) o número de citações desses trabalhos; (iv) os principais autores; ( $v$ ) os países dos autores que contribuíram com esses trabalhos; (vi) as principais fontes onde esses trabalhos foram publicados; (vii) as principais afiliações desses autores; (viii) o idioma em que esses trabalhos foram publicados; (ix) o tipo de cada documento; $(x)$ as palavras-chave mais utilizadas nos textos; (xi) os países que se destacam a nível mundial em publicações no tema; (xii) o índice resultante da divisão do número de citações pelo número de publicações; (xiii) o índice resultante da divisão do número de publicações pelo número, em milhões, de habitantes de cada país. Assim, escolheu-se P/Pop (número total de publicações dividido pelo número total da população do país) para verificar quantos artigos são produzidos por cada habitante da região e, também, o índice C/P (citações divididas por número total de publicações) para verificar o impacto desses artigos.

As buscas foram feitas no primeiro bimestre de 2021 (janeiro e fevereiro). No primeiro momento, procurou-se pelos trabalhos sobre "limitações digitais da educação a distância" nas bases de dados Scopus e 
Web of Science. Para que se encontrasse uma variada quantidade de artigos sobre diversas modalidades, as buscas foram feitas as palavras chave: "digital limitations and e-learning", em cada uma das bases de dados no título, resumo e palavras-chave. Essa busca inicial pode ser conferida no Quadro 2.

Quadro 2: Buscas nas bases de dados

\begin{tabular}{|c|c|c|c|}
\hline \multirow{2}{*}{ Fase da pesquisa } & \multicolumn{3}{|c|}{ Quantidade de artigos } \\
\cline { 2 - 4 } & Scopus & Web of Science & Total \\
\hline Busca inicial & 333 & 113 & 446 \\
\hline Artigos duplicados & & -42 & 404 \\
\hline Artigos que não estivessem no escopo da pesquisa & & -29 & 375 \\
\hline \multicolumn{2}{|c|}{ Artigos analisados no portfólio bibliométrico } & 375 \\
\hline
\end{tabular}

Fonte: Elaborado pelos autores, com base na pesquisa realizada.

Em primeiro momento, as pesquisas foram feitas apenas utilizando os termos "digital limitations and e-learning", nas três bases de dados. Essas pesquisas geraram um total de 446 artigos.

Tendo em vista que o tema foi procurado em duas bases de dados diferentes, por diversos momentos o mesmo artigo aparece indexado em mais de uma base de dados. Partindo desse material, a etapa seguinte dedicou-se na detecção e remoção de artigos duplicados. Esse trabalho permitiu a retirada de um total de 42 , liberando para a análise mais detalhada um total de 404 artigos.

Em uma terceira etapa, foram removidos os trabalhos que, apesar de conter os termos "digital limitations and e-learning", não se dedicassem a analisar limitações digitais e/ou educação a distância. Este recorte foi interessante, pois permitiu a retirada de artigos que estivessem intrinsecamente conectados com áreas como engenharia da computação e aproximou os resultados da área da Educação. Desta etapa, foram removidos 29 artigos, permitindo a finalização do portfólio bibliométrico em 375 artigos.

\section{Discussão dos Resultados Bibliométricos}

Para analisar os resultados obtidos na primeira fase, os resultados foram organizados em categorias, sendo a evolução das pesquisas por ano de publicação, os países mais produtivos, as instituições mais produtivas, os tipos de documentos e fontes mais produtivos, os autores que mais publicaram e os idiomas mais utilizados.

Objetivando mensurar o progresso de produção científica da amostra analisada com relação a consumo sustentável e inovação, na publicação mundial, construiu-se um histograma de acordo com o número de publicações identificadas por ano, conforme por ser visualizado no Gráfico 1.

Gráfico 1: Evolução temporal das publicações sobre o tema limitações digitais da educação a distância, no período 2004/2021.

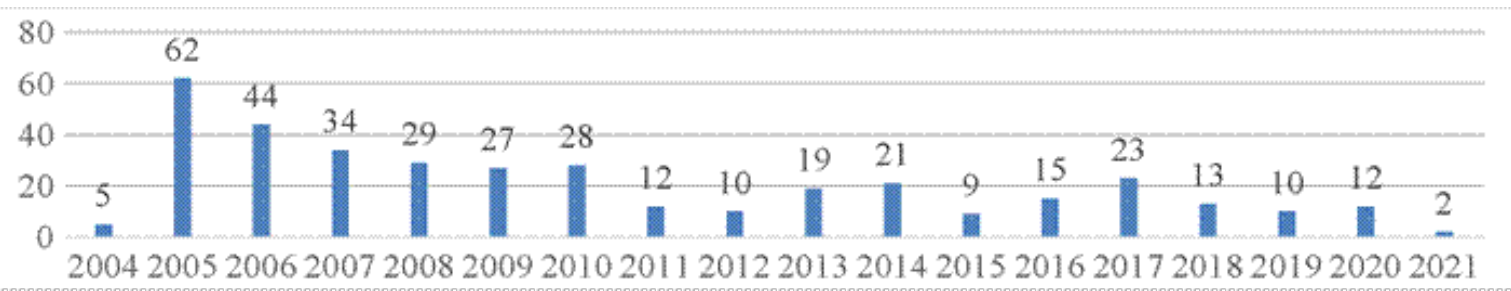

Fonte: Elaborado pelos autores, com base na pesquisa realizada. 
cio da década de 2000, com o primeiro artigo sendo publicado no ano de 2004. 0 interesse pela pesquisa mantém-se, dessa forma, pelas décadas seguintes, havendo um discreto decrescimento no interesse pela temática a partir da década de 90. Esse interesse cresce novamente de forma discreta na década de 2010. De todo esse período, destaca-se o ano de 2005, com 62 artigos publicados.

Considerando a distribuição geográfica das publicações, foram verificados os países com maiores quantidade de produções sobre "limitações digitais da educação a distância" em nível mundial. Foi realizada uma contagem simples da quantidade de artigos publicados em cada país, atribuindo-se uma frequência de um para cada publicação, e depois juntando e somando as recorrências; logo após esses dados, foram organizados em ordem decrescente de resultados, ou seja, do país que tem mais artigos publicados para o que tem menos.

Tendo em vista que a amostra de artigos analisada resultou em artigos publicados em 31 países diferentes e a grande maioria deles com apenas um artigo publicado, optou-se por analisar apenas aqueles que tivessem no mínimo dez artigos publicados, resultando assim, no "ranking" os onze países mais produtivos. Justifica-se esta escolha pelos onze países tendo em vista que estes países são $35,48 \%$ do total de países da amostra e a quantidade publicada total por estes (226 artigos) representa 60,26\% de todas as publicações da amostra. Além dos dados de publicações, foram incluídos os indicadores de quantidade de citações dividida pela quantidade de publicações (C/P) e a quantidade de publicações dividida pela população do país em milhões de habitantes (P/Pop). Estes dados podem ser percebidos no Quadro 3.

Quadro 3: Ranking dos 11 países com maior produção de artigos relacionados a limitações digitais da educação a distância, no período 2004/2021.

\begin{tabular}{|c|c|c|c|c|c|c|}
\hline Ranking & País & $\mathbf{N}^{0}$ de publicações & $\mathbf{N}^{\circ}$ de citações & C/P & Pop & P/Pop \\
\hline $\mathbf{1}$ & Portugal & 16 & 19 & 1,19 & 10,27 & 1,56 \\
\hline $\mathbf{2}$ & Taiwan & 25 & 445 & 17,80 & 23,60 & 1,06 \\
\hline $\mathbf{3}$ & Espanha & 29 & 168 & 5,79 & 47,10 & 0,62 \\
\hline $\mathbf{4}$ & Austrália & 15 & 139 & 9,27 & 25,69 & 0,58 \\
\hline $\mathbf{5}$ & Reino Unido & 31 & 258 & 8,32 & 66,44 & 0,47 \\
\hline $\mathbf{6}$ & Canadá & 11 & 103 & 9,36 & 38,01 & 0,29 \\
\hline $\mathbf{7}$ & Itália & 14 & 134 & 9,57 & 60,23 & 0,23 \\
\hline $\mathbf{8}$ & Estados Unidos & 42 & 446 & 10,62 & 329,63 & 0,13 \\
\hline $\mathbf{9}$ & Brasil & 11 & 27 & 2,45 & 210,14 & 0,05 \\
\hline 10 & China & 19 & 48 & 2,53 & 1402,50 & 0,01 \\
\hline 11 & Índia & 13 & 62 & 4,77 & 1361,86 & 0,01 \\
\hline
\end{tabular}

Legenda:

C/P: quantidade de citações dividida pela quantidade de publicações

Pop: população do país em milhões (conforme portal Index Mundi - https://www.indexmundi.com/).

P/Pop: quantidade de publicações dividida pela população do país em milhões de habitantes

Fonte: Elaborado pelos autores, com base na pesquisa realizada.

A liderança na quantidade de estudos sobre limitações digitais da educação a distância, nesse período de 2004 a 2021 é dos estados Unidos, detendo 42 dos 375 artigos do portfólio bibliométrico, totalizando assim $11,20 \%$ de toda a amostra, no qual, contabilizam 446 citações aos seus estudos.

Todavia, ainda que seja relevante a quantidades de publicação da temática por país, os dados de citações por quantidade de artigos publicados são importantes por demonstrar os interesses da academia 
nas pesquisas desenvolvidas. Neste quesito, apresenta-se Taiwan, uma vez que com apenas 25 artigos publicados obteve um total de 445 citações, ficando com um indicador de 17,80 citações por artigo. Na sequência, têm-se os Estados Unidos, com um indicador de 10,62. Dessa forma, os países mais citados são Taiwan e Estados Unidos.

Direcionando a análise, a fim de perceber o interesse de pesquisa dos países pelo tema, tem-se o indicador P/Pop, que verifica a quantidade de publicações dividida pela população do país em milhões de habitantes. Nesse momento, tem-se Portugal como o país mais interessado em pesquisar sobre a temática, com um índice P/Pop de 1,56. Na sequência, Taiwan volta a aparecer em destaque, com o indicador de 1,06. Dessa forma, os países mais interessados por pesquisas sobre limitações digitais da educação a distância são Portugal e Taiwan.

Tendo em vista que estes indicadores apresentam a preponderância mundial na pesquisa, é válido destacar a presença da produção científica nacional uma vez que o Brasil aparece entre os 10 países com maiores publicações sobre a temática, tendo publicado 11 artigos com 27 citações.

No que diz respeito às instituições de onde são provenientes estas publicações, foram observadas 310 instituições, sendo que, foram elencadas as 13 instituições que apresentaram mais de 2 publicações, representando 4,19\% de todas as instituições observadas e responsáveis por 13,06\% de todos os trabalhos publicados (49 artigos). O resultado desta etapa pode ser conferido a seguir, no Quadro 4.

Quadro 4: Ranking das 13 Instituições com mais de 2 publicações sobre o tema limitações digitais da educação a distância, no período 2004/2021.

\begin{tabular}{|c|c|c|c|}
\hline Ranking & Instituição & País & $\mathrm{N}^{\circ}$ de publicações \\
\hline 1 & Nanyang Technological University & Singapura & 6 \\
\hline 2 & National Taiwan University of Science and Technology & Taiwan & 5 \\
\hline 3 & Sultan Qaboos University & Omã & 5 \\
\hline 4 & $\begin{array}{l}\text { Wee Kim Wee School of Communication and } \\
\text { Information }\end{array}$ & Singapura & 5 \\
\hline 5 & Aristotle University of Thessaloniki & Grécia & 4 \\
\hline 6 & Natl Chengchi University & Taiwan & 3 \\
\hline 7 & Bowling Green State University & $\begin{array}{l}\text { Estado } \\
\text { Unidos }\end{array}$ & 3 \\
\hline 8 & Deakin University & Austrália & 3 \\
\hline 9 & Harbin Institute of Technology & China & 3 \\
\hline 10 & National Chengchi University & Taiwan & 3 \\
\hline 11 & Open University of The Netherlands & Holanda & 3 \\
\hline 12 & Universidade do Porto & Portugal & 3 \\
\hline 13 & University of South Africa & África do Sul & 3 \\
\hline
\end{tabular}

Fonte: Elaborado pelos autores, com base na pesquisa realizada.

Destaca-se Taiwan como o país com as instituições mais produtivas. Juntas, as instituições representam 23,07\% das treze instituições mais produtivas. São três as instituições de Taiwan: National Taiwan University Of Science And Technology; Natl Chengchi University; National Chengchi University, com cinco, três e três trabalhos publicados, respectivamente. 
A fim de consolidar os autores mais produtivos, foi realizada a contagem de cada autor presente nos artigos. Dos 375 autores, elencou-se um total de 324 autores, onde apenas três tiveram mais do que três artigos publicados. São estes: Dr. José António Marques Moreira - pesquisador da Universidade Aberta do Porto (Portugal); Dr. Chih-Ming Chen - pesquisador da National Chengchi University (Taiwan) e Dra. Ana Machado - Pesquisadora da Universidade Aberta de Lisboa (Portugal).

Outra informação relevante vem a ser os periódicos (journals) que mais têm publicado acerca da temática. O recorte deu-se a fim de destacar apenas os que tivessem mais de nove publicações cada. Para isso, apresentam-se dos 107 journals elencados, os três mais profícuos. Estes podem ser conferidos a seguir, no Quadro 5. A escolha por estes três deu-se para contemplar as que tivessem mais do que nove artigos publicados cada uma.

Quadro 5: Periódicos mais profícuos

\begin{tabular}{|c|c|c|c|}
\hline Ranking & Periódico & País & N $^{\circ}$ de publicações \\
\hline 1 & Lecture notes in computer science & Alemanha & 18 \\
\hline 2 & ACM International Conference Proceeding Series & Estados Unidos & 10 \\
\hline 3 & Electronic Library & Estados Unidos & 10 \\
\hline
\end{tabular}

Fonte: Elaborado pelos autores, com base na pesquisa realizada.

Por fim, averiguaram-se quais os tipos de documentos e em que idiomas estes são recorrentemente mais publicados. Dos 375 estudos analisados, 50,4\% (189 estudos) foram publicados em anais de eventos; 43,73\% (164) publicados em journals; 3,73\% (14) artigos de revisão da literatura e 2,13\% (8) publicados como capítulos de livro. Quanto ao idioma: 96,8\% de toda a publicação (363) foram publicados em inglês. Na sequência, 1,06\% (4) em espanhol, e com 0,8\% (três artigos cada), aparecem artigos publicados em árabe e português. Depois, representando apenas um artigo cada, aparecem o francês e o russo.

\section{Educação Não Presencial: Discussão dos Tipos}

Os textos encontrados durante a busca bibliométrica discutiram tipos importantes e relevantes sobre onde se tem pesquisado limitações digitais na educação presencial. Todavia, diante dos achados, tornou-se relevante uma exposição de quatro tipos de educação definidos pelos autores como "educação não presencial". Alguns destes estão envolvidos entre outros; todavia, nessa pesquisa, decidiu-se apresentar esses modelos em quatro, a saber, (i) A educação a distância; (ii) A educação presencial apoiada pelas TIC; (iii) A educação presencial com 20\% de sua operacionalização a distância; (iv) A educação emergencial remota.

\subsection{Educação a distância}

A educação a distância passou a ganhar fôlego e caminhar em direção à institucionalização nas IFeS a partir de 2006, quando foi criado pelo governo federal o programa Universidade Aberta do Brasil. Hernandes (2017) explica que a UAB foi criada pelo Ministério da Educação (MEC) ainda em 2005, mas veio a ser regulamentado apenas através do Decreto 5.800, de 8 de junho de 2006. Este decreto lançou os fundamentos do projeto UAB ao constituir uma parceria entre os três níveis governamentais, as IFES e os demais interessados com o objetivo de oferecer cursos de ensino superior na modalidade a distância. Através da cada vez maior popularização do acesso à internet na década de 2000, estariam disponíveis formas de articular interações docente-discente e discente-discente em formato síncrono e/ou síncrono.

Já no $1^{\circ}$ artigo do decreto que institui o sistema $U A B$, aparece que a finalidade do programa seria buscar, através do desenvolvimento da modalidade a distância, expandir e interiorizar a oferta de cursos e 
programas de educação superior no Brasil (BRASIL, 2006). Através do emprego de TIC, a educação viria a ser expandida entre lugares onde a educação presencial não teria como chegar. Como uma resposta a um dos anseios do Plano Nacional de Educação (PNE), que em 2001 buscava empregar os meios tecnológicos para expansão e interiorização do ensino superior público e de qualidade no Brasil (BRASIL, 2001).

A EaD enquanto modalidade dispõe de regulamentação específica, definindo diretrizes para sua operacionalização. $\mathrm{Na} \mathrm{EaD} \mathrm{várias} \mathrm{metodologias} \mathrm{podem} \mathrm{ser} \mathrm{utilizadas,} \mathrm{como} \mathrm{o} \mathrm{uso} \mathrm{de} \mathrm{sistemas} \mathrm{on-line,} \mathrm{de}$ forma síncrona - o que pode ser chamado de educação on-line. Mas também a utilização de ferramentas assíncronas e analógicas, como os materiais impressos (ARRUDA, 2020). Distinto isso, a EaD é todo um arcabouço de tecnologias, legislações e atores que permitem a operacionalização do processo de ensino-aprendizagem acontecer todo em si mesmo, sem a presença física de seus atores.

A EaD envolve um planejamento anterior, considerações sobre os perfis de docentes e discentes, desenvolvimento a médio e longo prazo de estratégias de ensino aprendizagem que possibilitem as interações síncronas e assíncronas, o envolvimento de diversos profissionais que contribuam com o desenvolvimento da prática pedagógica com qualidade (MAIA; MATTAR, 2008).

\subsection{A educação presencial apoiada pelas TIC}

O segundo formato educacional não presencial discutido apresenta-se como sendo a educação presencial apoiada pelas TIC. Görgens e Andrade (2020) explicam que a redução de custo dos artefatos tecnológicos, a crescente expansão de acesso à internet tem tocado a educação presencial, sugerindo algumas adequações aos formatos mais tradicionais para essa utilização de tecnologia nas aulas. Ainda para os autores, a maior parte das IES dispõe de uma extensa rede de computadores com acesso à internet, pontos de acesso à internet (como o wireless) e outros. Estes passaram a ser incorporados à cultura do ensino presencial, tornando-se uma ferramenta paralela através dos ambientes de ensino e aprendizado - operados através dos ambientes virtuais de aprendizagem (AVA).

Miranda (2007) desenvolve que não é nova a incorporação de novas tecnologias, uma vez que o ensino formal vem incluindo diversos apoios externos na operacionalização das aulas, como a indicação de livros não didáticos, indicação e exibição de filmes nas salas de aula. Para Espinosa e Cartagena (2021), a rapidez das mudanças tecnológicas torna necessária a investigação de novos modelos e estratégias de ensino-aprendizagem que facilitem a assimilação dessas mudanças tecnológicas no menor tempo possível e os capacitem para as novas demandas do mercado de trabalho.

Nesse sentido, a internet aparece como uma unificação destes esforços, permitindo a organização destes materiais em um único espaço, em que os atores da educação possam transpor parte do que acontece no mundo físico para o mundo digital, permitindo o melhor uso do espaço e tempo físico para atividades em que é necessária essa configuração - como atividades práticas.

Imerso nesse modelo híbrido, que nesse estudo está sendo chamado de "educação presencial apoiada pelas TIC", o docente precisa seguir comunicando-se com os discentes presenciais também on-line. Moran (2015) explica que essa mescla entre sala de aula e ambiente virtual é fundamental para o processo de ensino-aprendizagem acontecer de forma efetiva em tempos de tanta destreza digital, por parte dos discentes. Através de práticas, atividades, jogos e construção de projetos no formato on-line, os discentes podem aprender fazer uma combinação entre aprender junto com os colegas e professores.

\subsection{A educação presencial com 20\% de sua operacionalização a distância}

Gomes (2018) traça um desenvolvimento temporal para explicar a possibilidade de adesão de $20 \%$ de EaD para os cursos presenciais. A autora apresenta que a primeira publicação que regulamentou o 
acoplamento entre a educação presencial e a EaD no ensino superior foi a Portaria 2.253/2001, esta concretizou o objetivo do MEC de acelerar a implementação da EaD nos cursos de graduação presenciais.

Todavia, ainda de forma tímida, a portaria permitia que essa oferta experimental de 20\% EaD só poderia acontecer nos cursos que já tivessem seu reconhecimento junto ao MEC. Além de abrir a possibilidade, a portaria delimitou que a oferta de EaD nos cursos presenciais não poderia ultrapassar os $20 \%$ para a integralização do currículo destes cursos. Além disso, as disciplinas que fossem ser oferecidas nesses $20 \%$ deveriam também ser oferecidas em formato presencial, e apenas as universidades e os centro universitários poderiam aderir aos 20\% (GOMeS, 2018).

Ainda a autora explica que em 2004, já em um novo governo, foi publicada a Portaria 4.059/2004, onde a implementação dos $20 \%$ se ampliou consideravelmente entre as IES, uma vez que a exigência de ofertar as disciplinas no formato presencial e não presencial (o que gerava mais custos às IES) foi excluída. Além disso, todas as IES poderiam articular esses $20 \%$, cabendo apenas a exigência de solicitar essa liberação ao MEC. A seguir, o Quadro 6 apresenta as principais diferenças na evolução das exigências entre as portarias.

Quadro 6: Comparativo das Portarias de Regulação 20\% a distância.

\begin{tabular}{|c|c|c|c|}
\hline Categoria & Portaria 2.253/2001 & Portaria $4.059 / 2004$ & Portaria 1.134/2016 \\
\hline $\begin{array}{l}\text { Carga horária } \\
\text { máxima }\end{array}$ & $20 h$ & $20 h$ & $20 h$ \\
\hline Metodologia & $\begin{array}{l}\text { Métodos e práticas de } \\
\text { ensino-aprendizagem } \\
\text { que incorporem o uso } \\
\text { integrado de tecnolo- } \\
\text { gias de informação e } \\
\text { comunicação para a } \\
\text { realização dos objeti- } \\
\text { vos pedagógicos. }\end{array}$ & $\begin{array}{c}\text { Métodos e práticas de } \\
\text { ensino-aprendizagem que } \\
\text { incorporem o uso integrado } \\
\text { de tecnologias de informa- } \\
\text { ção e comunicação para } \\
\text { a realização dos objetivos } \\
\text { pedagógicos, bem como } \\
\text { prever encontros presen- } \\
\text { ciais e atividades de tutoria. }\end{array}$ & $\begin{array}{c}\text { Mesma redação da } \\
\text { Portaria nº 4.059/2004 }\end{array}$ \\
\hline
\end{tabular}

Fonte: adaptado de Gomes (2018). 


\subsection{Educação emergencial remota (Covid-19)}

Motivados pela pandemia do Covid-19, as IES precisaram tomar decisões rápidas sobre um plano para a continuidade de suas atividades em um formato não presencial. Arruda (2020) explica que há uma confusão nas denominações do modelo, chamado por alguns como educação on-line, educação a distância, e mesmo educação remota. Para o autor, apesar de serem colocados como sinônimos, os termos implicam coisas diferentes. Enquanto a educação a distância pressupõe o formato como um meio em si mesmo, a educação remota vem a ser uma resposta rápida e elaborada emergencialmente para o período pandêmico.

Assim, a educação remota aparece como uma terceira via: EaD, educação presencial (com 20\% EaD ou amparada pelas TIC) e educação remota. Hodges et al. (2020) explicam que essa aparece no movimento feito no caráter emergencial em apropriar-se de tecnologias em circunstâncias específicas para atender um público que outrora operava em um formato presencial.

Já a educação remota emergencial aparece como uma mudança temporária da entrega dos conteúdos curriculares antes presenciais para um formato alternativo em resposta a uma crise. Esse novo formato faz uma combinação entre práticas dos modelos presenciais e EaD e objetivam manter-se assim pelo tempo que a crise sanitária do Covid-19 durar (HODGeS et al., 2020).

\section{Conclusões e encaminhamentos}

O estudo apresentado teve por objetivo analisar os indicadores da produção científica mundial acerca das limitações digitais em educação a distância. Para isso, foi performada uma pesquisa bibliométrica nas bases de dados Scopus e Web of Science, cujos dados foram tratados até formar-se um portfólio bibliométrico de 375 artigos. Destes, diversas análises foram feitas, como a evolução temporal, onde destacam-se os anos de 2001 a 2010, com maior preocupação em entender as limitações digitais na Educação, em que as pesquisas foram lideradas pelos Estados Unidos, Reino Unido, Espanha e Taiwan. Quanto às instituições e journals mais produtivos, destaque para a Nanyang Technological University, de Singapura, e Lecture Notes in Computer Science, da Alemanha - respectivamente. Quase a totalidade desses artigos está publicada em inglês.

Um destaque a Taiwan, que se apresenta entre os países com maiores publicações, bem como maiores índices de citações em relação à produção e dos melhores índices na relação entre a publicação e o tamanho da população, demonstrando o interesse e a relevância das pesquisas desenvolvidas pelas suas instituições.

Digno de maiores considerações, vem a ser o fato de que a maior parte dos estudos aparece publicada em anais (proceedings) de eventos científicos em primeiro lugar, para só em segundo lugar aparecerem os estudos publicados em periódicos. Infere-se de certa forma um tema novo de pesquisa, ainda em amadurecimento no campo das publicações, uma vez que a prioridade está na escuta dos avaliadores destes eventos. A educação a distância vem ganhando cada vez mais forma e aceitação a partir da entrada do século XXI e com isto, tem gerado o interesse de pesquisa em diversas lentes epistemológicas.

Nesta pesquisa, entendeu-se a busca por limitações digitais, a fim de entender o movimento destas publicações e poder-se aprofundar o estudo de que limitações seriam essas, de que formas estas podem ser classificadas e mitigadas, para assim possibilitarem cada vez uma melhor execução da educação a distância, alcançando o mais variado público em seu intento. Limitações podem ser consideradas no estudo, quanto à possível variabilidade na escrita dos termos pesquisados, considerando as pesquisas realizadas em diferentes campos e abordagens de estudo, como também pela quantidade mínima de artigos encontrados nas bases citadas. 
Quanto aos diferentes modelos de educação não presencial que teoricamente foram apresentados, é válido destacar alguns pontos:

Sobre o modelo educação a distância (EaD) nas instituições públicas, como este operacionalizado através do fomento de bolsas para coordenadores, professores e tutores e desenvolvido dentro dos AVAs das IFES: essa modalidade viria a acontecer então em paralelo às atividades presenciais. As IFES criariam então os cursos de graduação EaD/UAB coordenados por professores de seu corpo docente efetivo, mas distribuindo a operacionalização das disciplinas entre esses professores e outros, externos à instituição, selecionados via editais para contrato temporário e remunerados via bolsas. Dessa forma, alguns professores destas IES podem não terem atuado em projetos que envolvessem EaD e o uso das TIC, gerenciando suas aulas apenas no formato de interação presencial.

Já em relação à educação presencial apoiada pelas TIC, Pereira et al. (2016) indicam que o professor pode utilizar as TIC a fim de externalizar os conteúdos trabalhados em sala de aula ou mesmo incorporar estes às suas aulas para estimular autonomia por parte do discente e contribuir assim com uma construção de educação reflexiva e que problematize a realidade, formando assim pessoas críticas. Ainda o autor explica que este processo contribui com uma reconstrução do modelo onde o professor é o detentor e transmissor do conhecimento e o discente apenas um receptor passivo. Há uma quebra nessa linha de atuação, colocando o professor como o mediador e o discente como protagonista do processo, construindo assim o seu próprio conhecimento de forma mais autônoma.

Quanto à educação presencial com 20\% de sua operacionalização a distância, foi em 2016, com a publicação da Portaria 1.134/2016, onde cresceu a autonomia das IES quanto a implementar os $20 \%$ na integralização de seus cursos, uma vez que as IES que possuíssem pelo menos um curso de graduação reconhecido pelo MEC podem introduzir, na organização pedagógica e curricular de seus cursos de graduação presenciais regularmente autorizados, a oferta de disciplinas na modalidade a distância, respeitando a exigência de não ultrapassar os 20\%. A portaria exige a atualização do projeto pedagógico dos cursos presenciais com oferta de disciplinas na modalidade a distância, para fins de análise e avaliação, quando do protocolo dos pedidos de reconhecimento e renovação de reconhecimento dos cursos.

Por fim, a educação emergencial remota (Covid-19) pode ser apresentada como semelhante à educação presencial, com práticas como a transmissão das aulas no mesmo período em que aconteceriam as aulas presenciais. Essa transmissão permite de certa forma a interação docente-discente e discente-discente, mas pode inibir essa interação entre os mais tímidos, uma vez que essas aulas podem estar sendo gravadas e pelo fato de que aquele que decide por apresentar-se no vídeo obtém a atenção de todos naquele momento. Ademais, nessa semelhança ao modelo presencial, a educação remota avança em alguns pressupostos do modelo EaD ao implementar ferramentas assíncronas de comunicação, como fóruns de discussão, além da ampla utilização de aulas gravadas e disponibilizadas para acesso posterior.

Por fim, sugere se que novas pesquisas sejam feitas nesta mesma temática, analisando quais os artigos mais citados nas referências dos artigos deste portfólio bibliométrico, quais os artigos com maior número de citações sobre a temática e uma análise detalhada do conteúdo destes artigos, a saber, objetivos, métodos e resultados.

\section{Referências}

ARAÚJO, R. F; ALVARENGA, L. The bibliometrics in theses and dissertations produced in Brazil (1987-2007). encontros Bibli: revista eletrônica de biblioteconomia e ciência da informação, v. 16, n. 31, 2011, p. 51-70.

ARRUDA, E. P. emergency remote education: elements for public policies in Brazilian education in Covid-19 
times. em Rede: Revista de educação a Distância, v. 7, n. 1, p. 257-275, 2020.

BARRAS, R. Towards a theory of innovation in services. Research policy, v. 15, n. 4, 1986, p. 161-173.

BELLINI, C. G. P.; GleBeLeN, e.; CASALI, R. R. B. Limfitações digitais. Informação \& Sociedade: estudos, v. 20, n. 2, 2010, p. 25-35.

BEZERRA, I. M. P. State of the art of nursing education and the challenges to use remote technologies in the time of corona virus pandemic. Journal of Human Growth and Development, v. 30, n. 1, 2020, p. 141-147.

BRASIL. Decreto $n^{\circ} 5.800$, de 8 de junho de 2006. Dispõe sobre o Sistema Universidade Aberta do Brasil UAB. Diário Oficial da União, 9 jun. 2006.

BRASIL. Lei N 10.172, de 9 de janeiro de 2001. Aprova o Plano Nacional de educação e dá outras providências. Diário Oficial da União, 10 jan. 2001.

BRASIL. Portaria $n^{\circ}$. 2.253, de 18 de outubro de 2001. Dispõe sobre a introdução nas instituições de ensino superior do sistema federal de ensino, na organização pedagógica e curricular de seus cursos superiores reconhecidos, a oferta de disciplinas que, em seu todo ou em parte, utilizem método não presencial. Diário Oficial da União, 19 out. 2001.

ESPINOSA, M. P.; CARTAGENA, F. C. Tecnologias avançadas para enfrentar o desafio da inovação educacional. RIED - Revista Ibero-americana de educação a Distância, v. 24, n. 1, p. 35-53, 2021.

GIL, A. C. Como elaborar projetos de pesquisa. 6. ed. São Paulo: Atlas, 2018.

GOMES, K. A. Controvérsias na política de $\mathbf{2 0 \%}$ a distância: a caixa-preta. Tese (Dourorado em educação). Universidade Federal de Santa Catarina, Florianópolis, 2018.

GÖRGENS, P.; ANDRADE, P. C. University education supported by digital information and communication technologies: some practical ideas. Revista Eletrônica Científica ensino Interdisciplinar, v. 6, n. 17, p. 267-280, 2020.

HERNANDES, P. R. A Universidade Aberta do Brasil e a democratização do ensino Superior público. Ensaio: Avaliação e Políticas Públicas em educação, v. 25, n. 95, p. 283-307, 2017.

HODGES, C.; MOORE, S.; LOCKEE, B.; TRUST, T.; BOND, A. The difference between emergency remote teaching and on-line learning. [2020]. Disponível em: https://er.educause.edu/articles/2020/3/the-difference-between-emergency-remoteteaching-and-on-line-learning. Acesso em 04 out. 2020.

HODGES, C. et al. The difference between emergency remote teaching and on-line learning. [2020]. Disponível em: https://er.educause.edu/articles/2020/3/the-difference-between-emergency-remoteteaching-and-on-line-learning. Acesso em 05 fev. 2021.

KLECUN, E. Bringing lost sheep into the fold: Questioning the discourse of the digital divide. Information Technology \& People, v. 21, n. 3, p. 267-282, 2008.

MAIA, C.; MATTAR, J. ABC DA EAD: a educação a distância hoje. Pearson Prentice Hall, 2008

MALHOTRA, N. Pesquisa de Marketing: uma orientação aplicada. 6. ed. São Paulo: Bookman, 2012.

MIRANDA, G. L. The limits and possibilities of ict in education. Sísifo - Revista de Ciências da educação, n. 3, p. 41-50, 2007.

MORAN, J. Mudando a educação com metodologias ativas. Coleção Mídias Contemporâneas, v. 2, n. 1, p. 15- 31, 2015. 
NOVELLO, T. P. et al. Limitações digitais e covid-19: práticas educativas emergentes nas novas formas de trabalho remoto. In: XII Congresso de Administração Sociedade e Inovação - CASI, 13. Rio de Janeiro, RJ. Anais Eletrônicos. 2021. 1-17.

NOVELLO, T. P. ; PEREIRA JUNIOR, E. F. Z.; RIBeIRO, N. F. Ambientes virtuais de aprendizagem: limitações digitais dos professores em época de pandemia do Covid-19. In: I Simpósio nacional de estratégias e multidebates da educação -SeMeDUC, 1. Online. Anais Eletrônicos, p. 481-487, 2020.

PEREIRA, T. A. et al. Uso das tecnologias de informação e comunicação por professores da área da saúde da Universidade Federal de São Paulo. Revista Brasileira de Educação Médica, v. 40, n. 1, p. 59-66, 2016.

PEREIRA JUNIOR, e. F. Z.; NOVELLO, T. P. Mapeamento das limitações digitais de professores durante o ensino remoto. Debates em Educação, v. 13, n. 31, p. 902-926, 2021.

PEREIRA JUNIOR, E. F. Z.; SCHROEDER, E. A.; DOLCI, D. B. Limitações digitais, causas e consequências na efetividade do uso do site trello no planejamento estratégico de uma secretaria de educação a distância de uma universidade federal. em Rede-Revista de Educação a Distância, v. 6, n. 1, 2019, p. 69-85.

RICHARDSON, R. J. Pesquisa Social: métodos e técnicas. 3. ed. São Paulo: Atlas, 2009.

ROCHA, T. B. O Plano de Aula para educação On-line na Pandemia de Covid-19. Revista EAD em Foco, V. 11, 2020. P. 1-20.

ROESCH, S. M. A. Projetos de estágio e de pesquisa em administração: guia para estágios, trabalhos de conclusão, dissertações e estudos de caso. São Paulo: Atlas, 2015.

SENHORAS, E. M. Coronavírus e educação: Análise dos Impactos Assimétricos. Boletim de Conjuntura, v. 2, n. 5, 2020, p. 128-136.

SOUZA, M.; RIBEIRO, A. L. Systematic review and meta-analysis of diagnostic and prognostic studies: a tutorial. Arquivo Brasileiro de Cardiologia, v. 92, n. 3, 2009, p. 241-251.

SPINELLI, A.; PELLINO, G. COVID-19 pandemic: perspectives on an unfolding crisis. The British journal of surgery, v. 107, n. 1, 2020, p. 785-787.

TELLO GAMARRA, J. et al. Innovation studies in Latin America: a bibliometric analysis. Journal of technology management \& innovation, v. 13, n. 4, p. 24-36, 2018

VAN DIJK, J.; HACKER, K. The digital divide as a complex and dynamic phenomenon. The information society, v. 19, n. 4, 2003, p. 315-326. 